\title{
Regeneration of atretic sheep ovarian follicles in vitro
}

\author{
Mary F. Hay, R. M. Moor, D. G. Cran and H. M. Dott \\ A.R.C. Institute of Animal Physiology, Animal Research Station, 307 Huntingdon Road, \\ Cambridge CB3 OJQ, U.K.
}

Summary. Large (4-6 $\mathrm{mm}$ diam.) and small $(2-3 \mathrm{~mm})$ atretic follicles were removed from sheep ovaries during the luteal phase of the cycle and maintained in organ culture without hormonal supplementation for up to 5 days. The structure, cell dynamics and steroid-producing capacity of the follicles were compared with those of non-atretic follicles of similar size.

The granulosa layer of the atretic follicles invariably regenerated in culture, increasing in thickness more than 2- and 4-fold in large and small follicles respectively. This could not be accounted for by cell division which remained low throughout the culture period. In contrast, non-atretic follicles showed high mitotic activity during the first $24 \mathrm{~h}$ in culture: this was not associated with an increase in granulosa thickness in large follicles although there was a 4-fold increase in small ones. An increase in internuclear spacing, a measure of cell size plus intercellular space, partly accounted for the increase in granulosa thickness in atretic follicles. Even when granulosa cells remained in close apposition there was an almost total absence of gap junctions, a prominent feature in the granulosa of non-atretic follicles both in vivo and in vitro. Pyknotic nuclei and atretic bodies rapidly disappeared from the regenerating granulosa layer. The theca interna was restored in culture to a state ultrastructurally closely resembling that of non-atretic follicles in vivo.

Total steroid secretion (oestradiol-17 $\beta$, testosterone plus progesterone) into the culture medium (pmol.mg tissue $\mathrm{e}^{-1} .24 \mathrm{~h}^{-1}$ ) was the same for atretic and non-atretic follicles of comparable size. There was, however, a marked difference in the type of steroid produced, largely related to a loss of aromatizing capacity in atretic follicles. The predominant steroid secreted by large non-atretic follicles was oestrogen, with slightly smaller amounts of testosterone, whereas the principal steroid secreted by large atretic follicles was progesterone. In small non-atretic and atretic follicles, the predominant steroid was testosterone, but the non-atretic follicles also secreted appreciable amounts of oestrogen. Addition of FSH to the culture medium did not restore aromatizing capacity to the atretic follicles.

\section{Introduction}

Atresia is the fate of the great majority of ovarian follicles. Once initiated, this process is progressive and finally results in the disappearance of a recognizable follicular structure. Several theories have been advanced to account for the induction of atresia (for review, see Greenwald, 1974). Amongst them is the possibility that the follicles fail to develop adequate hormone receptors (Richards, Rao \& Ireland, 1978) or that they respond adversely to specific changes in the maternal environment. Reduction in follicular blood supply leading to substrate limitation may also be involved (Hay, Cran \& Moor, 1976). It has been our purpose to examine follicles that have been removed from the maternal environment and maintained under favourable nutrient conditions in vitro. The effect of this procedure on the morphology, cell dynamics and function of non-atretic and atretic follicles has been investigated. 


\section{Materials and Methods}

\section{Preparation and culture of follicles}

Antral follicles $2 \cdot 0-3.0$ and $4.0-6.0 \mathrm{~mm}$ in diameter were dissected from the ovaries of sheep slaughtered between the 4 th and 14th days of the cycle at the local abattoir. The follicles were examined with a stereoscopic microscope and non-atretic and atretic follicles in the secondary and tertiary stages of atresia were identified using criteria previously described (Moor, Hay, Dott \& Cran, 1978). Follicles which fell into an intermediate ('indeterminate') class were discarded. Using these criteria, we have shown that non-atretic follicles can be identified with an accuracy of $93 \%$, and atretic ones with an accuracy of $83 \%$.

The dissected follicles were categorized as large $(4.0-6.0 \mathrm{~mm}$ diam.) non-atretic, large atretic, small (2.0-3.0 mm diam.) non-atretic and small atretic. Twenty (20) follicles of each category were cultured singly for 5 days on stainless-steel grids in plastic Petri dishes containing enriched medium 199; the gas phase consisted of $45 \% \mathrm{O}_{2}, 5 \% \mathrm{CO}_{2}$ and $50 \% \mathrm{~N}_{2}$ (for details see Moor, Hay, McIntosh \& Caldwell, 1973). A further 11 large atretic follicles were cultured in a similar manner in medium supplemented with FSH (FSH-NIH-S9, $2 \mu \mathrm{g} \cdot \mathrm{ml}^{-1}$ ). The culture medium was changed daily; after removal, the medium from each follicle was stored at $-20^{\circ} \mathrm{C}$, and subsequently analysed for steroid hormones. At the end of the 5-day culture period the follicles were fixed in Bouin's fluid for histological examination.

An additional 107 non-atretic and 116 atretic follicles were fixed after shorter periods of culture, ranging from 6 to $72 \mathrm{~h}$, for analysis of cell dynamics. Colcemid (Grand Island Biological Co., New York, U.S.A.) was added to the culture medium $6 \mathrm{~h}$ before fixation to give a concentration of $0.3 \mu \mathrm{g} . \mathrm{ml}^{-1}$. Paraffin-wax sections $(5 \mu \mathrm{m})$ taken from the equatorial region of the follicles were stained with the Martius scarlet-blue (MSB) trichrome method (Lendrum, Fraser, Slidders \& Henderson, 1962) and also by the Feulgen reaction, and were analysed with the aid of an image-analysing computer (Quantimet 720: Cambridge Instrument Co., Melbourn, Herts, U.K.). In the in-vitro conditions used, the lower part of the follicle which rested on the grid started to show degenerative changes within about $48 \mathrm{~h}$ (see Moor et al., 1973: Fig. 2). All observations were therefore made on the upper part of the follicle, and included the tissue at the gas/medium interface, the site where culture conditions are optimal. In each stained preparation, at least 2000 granulosa cells were examined when possible; the numbers of cells in metaphase, pyknotic nuclei and small atretic bodies (free pyknotic nuclei) were counted. The area occupied by these 2000 cells was measured and the thickness of the granulosa layer determined. The area associated with each nucleus (internuclear space) was also calculated; it represents cell size plus intercellular space.

Ultrastructural changes occurring during the culture period were studied in 42 follicles (12 non-atretic and 30 atretic) that had been cultured for 1-5 days. The follicles were fixed intact in $4 \%$ glutaraldehyde in $0.2 \mathrm{M}$-collidine buffer, $\mathrm{pH} 7.2$, in which they were subsequently cut into small segments that were then processed using the standard procedure described by Hay $e t$ al. (1976); the tissue was block stained in uranyl acetate and embedded in Epon.

The localization of the enzyme $\Delta^{5}-3 \beta$-hydroxysteroid dehydrogenase (3 $\beta$-HSD) was examined histochemically, using dehydroepiandrosterone as substrate, in 63 follicles that had been cultured for 1-5 days (see Hay \& Moor, 1975a, for methodological details).

Steroid production in vitro by the thecal shell and granulosa cells of large follicles was studied using the procedure described by Moor (1977).

\section{Steroid assays}

The amount of unconjugated oestrogen (predominantly oestradiol-17 $\beta$ ), testosterone and progesterone secreted into the culture medium was determined by radioimmunoassay (for details see Moor, 1977); the results are expressed in pmol steroid.mg wet weight of follicular tissue $\mathrm{e}^{-1} .24 \mathrm{~h}^{-1}$. 
The limit of sensitivity and the between-assay coefficient of variation for the present assays were: oestrogen $0.036 \mathrm{pmol} . \mathrm{ml}^{-1}$ and $7 \%(n=11)$; testosterone, $0.052 \mathrm{pmol} . \mathrm{ml}^{-1}$ and $8 \%$ $(n=11)$; and progesterone, $0.095 \mathrm{pmol} . \mathrm{ml}^{-1}$ and $12 \%(n=11)$.

\section{Cell dynamics and statistical analyses}

Histology. No statistical differences were found between analyses made on MSB- and Feulgen-stained sections and therefore the results obtained on the two types of preparation were pooled.

Mitotic activity was quantitated by determining the percentage of cells in metaphase after treatment of follicles in vitro with Colcemid for $6 \mathrm{~h}$. The pyknotic index was defined as (the number of pyknotic nuclei and atretic bodies/the number of euchromatic nuclei in a given area) $\times 100$.

Student's $t$ test was used to determine the significance of difference between means, and the F test for the differences between variances. The linear regression of granulosa thickness with time in culture was calculated by the method of least squares.

Steroid production. For statistical analysis, individual steroids were expressed as a proportion of total steroid secretion (oestradiol-17 $\beta+$ testosterone + progesterone) and transformed to angles. The Student $t$ test was used to compare means of total steroids and the transformed means of individual steroids. An analysis of variance was performed on rates of steroid production by large and small, non-atretic and atretic follicles cultured for 1, 3 and 5 days; the data were transformed to logs to normalize the distribution.

\section{Follicular morphology}

\section{Results}

Non-atretic follicles. The thickness of the granulosa layer in large follicles in vitro remained the same throughout the culture period and was not different from that observed in antral follicles in vivo $(56 \pm 2 \mu \mathrm{m}$ for follicles between 2 and $6 \mathrm{~mm}$ in diameter; M. F. Hay, unpublished observations). By contrast, the thickness of the granulosa layer in small follicles in vitro showed a 4-fold linear $(b=2 \cdot 13)$ increase during the first $72 \mathrm{~h}$ after explantation (Text-fig. 1). Apart from this difference in thickness, the structure of the granulosa layer during the first 3 days in culture was virtually indistinguishable from that already described in uncultured nonatretic follicles (Bjersing et al., 1972; Hay \& Moor, 1975b); as in follicles in vivo, gap junctions were a prominent feature. Occasional degenerate cells with pyknotic nuclei were seen. The appearance of the theca throughout the 5-day culture period was similar to that previously described for non-atretic follicles in vivo (O'Shea, Cran, Hay \& Moor, 1978b) apart from more rounded cellular profiles, the presence of occasional degenerating cells and an increased frequency of dividing cells. Cell counts made on follicles that had been cultured for $72 \mathrm{~h}$ showed that, as in vivo, approximately $35 \%$ of the thecal cells were well differentiated in terms of being rich in tubular endoplasmic reticulum (ER).

Atretic follicles. At the time of explantation, the majority of the atretic follicles were in the secondary or tertiary stages of atresia (Pl. 1, Fig. 1) and therefore showed some variation in degree of cellular degeneration, which was, in turn, reflected in the structure of the follicles during culture. In vitro, the follicles exhibited a remarkable capacity for regeneration of the granulosa layer, and in only one of the 85 follicles cultured for more than $60 \mathrm{~h}$ was there an absence of a well developed granulosa layer. The granulosa thickness increased linearly with time in both large $(b=1.40)$ and small $(b=2.58)$ follicles (Text-fig. 1), but the rate of increase was signifcantly greater in the small follicles $(t=5.384 ; 51$ d.f.; $P<0.001)$. There was, however, no difference between the rate of increase of granulosa thickness in the small atretic follicles as compared with the small non-atretic follicles. 


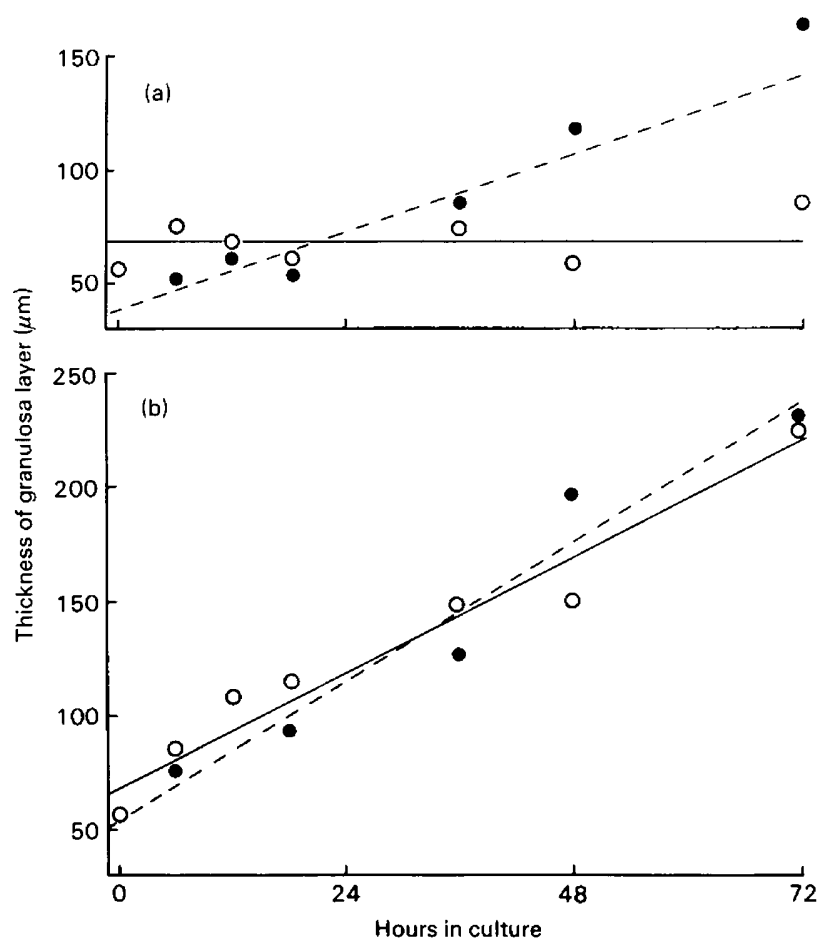

Text-fig. 1. Mean thickness of granulosa layer in histological sections of four different types of ovine follicles cultured for $6-72 \mathrm{~h}$. The follicles were exposed to Colcemid for $6 \mathrm{~h}$ before fixation. (a) Large (4-6 mm diam.) and (b) small (2-3 mm diam.) non-atretic (O) and atretic (O) follicles. Regression lines for granulosa thickness with time in culture are $y=67 \cdot 6+0.088 x$ for non-atretic large follicles $(\mathrm{a}, \longrightarrow), y=69 \cdot 2+2 \cdot 13 x$ for non-atretic small follicles $(\mathrm{b},-\longrightarrow)$, $y=38.9+1.4 x$ for atretic large follicles $(\mathrm{a},---)$, and $y=55.1+2.58 x$ for atretic small follicles (b, ---).

After $72 \mathrm{~h}$ in culture two main forms of regeneration of the granulosa layer could be identified although intermediates were seen. The most common form is illustrated in Pl. 1, Fig. 3. In the light microscope the cells appeared compact but in the electron microscope prominent intercellular spaces were seen, particularly in the region of the antrum. However, neighbouring cells generally came into close apposition at some point along their surfaces. The borders of the cells were irregular with numerous cytoplasmic evaginations. In marked contrast to cultured non-atretic follicles, gap junctions were rare. In some follicles regeneration seemed to be taking place at two levels, from the basal cells that had remained attached to the basal lamina and also from the inner granulosa layer that had become partly detached during atresia (Pl. 1, Fig. 3). Free pyknotic nuclei were frequently trapped between the two zones of cell regeneration. After 4 or 5 days in culture some of the granulosa cells in follicles of this type often appeared to have luteinized, having an increased cytoplasmic/nuclear ratio. In Pl. 1, Fig. 4 the second type of regeneration is illustrated: the cells forming the granulosa layer are elongated and spindleshaped. This type of regeneration was more common in the larger follicles. Occasionally both types of regeneration occurred in the same follicle.

The fine structure of the cytoplasm of the regenerating granulosa cells did not differ in any major regard from that in non-atretic follicles. However, from an examination of many follicles it was clear that, in general, they possessed a greater number of Golgi complexes, lipid droplets, microtubules, microfilaments and lysosomes than did the granulosa cells of non-atretic follicles. 


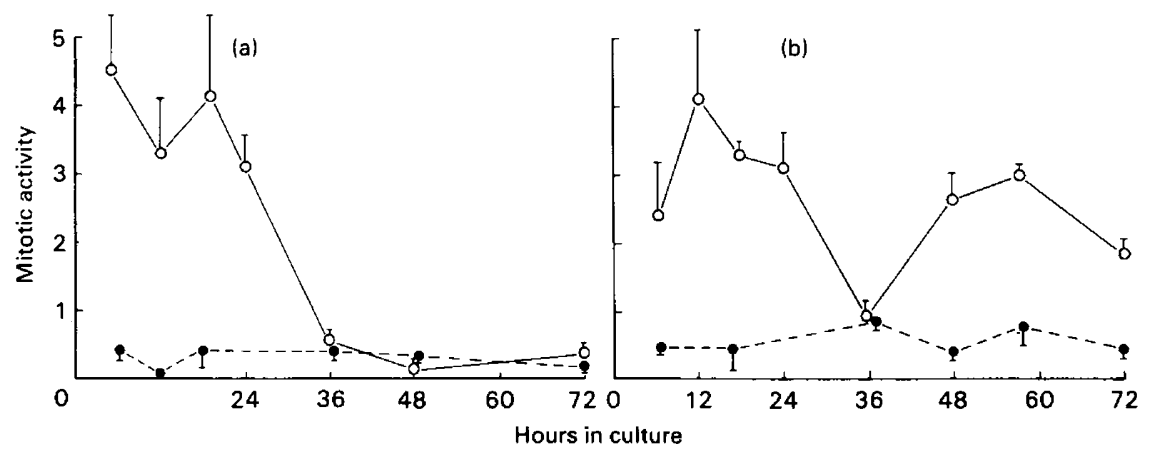

Text-fig. 2. Mean mitotic activity (\% of cells in metaphase after $6 \mathrm{~h}$ exposure to Colcemid) \pm 1 s.e.m. in the granulosa of cultured ovine follicles, (a) large (4-6 mm diam.) and (b) small (2$3 \mathrm{~mm}$ diam.), which were non-atretic $(\mathrm{O}-\mathrm{O})$ or atretic $(\mathbf{- - - 0})$.

In the atretic follicles, some of the granulosa cells were highly phagocytic and often contained large amounts of cellular debris.

The basal lamina which separated the granulosa layer from the theca interna is thickened in atretic follicles in vivo (see Hay et al., 1976: Fig. 17) compared with that of non-atretic ones, but remains largely intact. In culture the basal lamina became thicker and more irregular, often showing a reticular structure and penetrating some distance into both the theca and granulosa layers. No clearly identifiable gaps were observed in the basal lamina but occasional thecal and granulosa cells appeared to be passing through it. In several follicles collagen was present on both sides of the basal lamina and also within the lamina itself (Pl. 1, Fig. 2).

In the theca interna of atretic follicles in vivo, cell deletion occurs as a result of apoptosis and phagocytic bodies are a prominent feature (O'Shea, Hay \& Cran, 1978a). When atretic follicles were cultured many phagocytic bodies were still present at $60 \mathrm{~h}$, but after 4 days in culture they

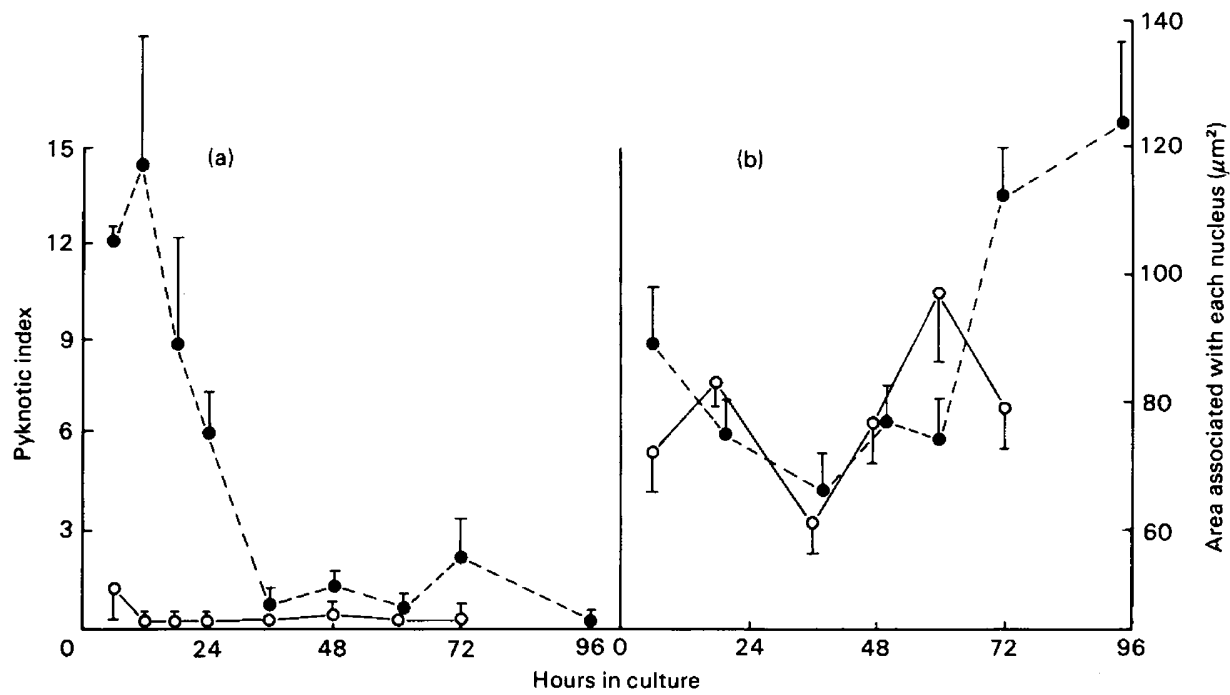

Text-fig. 3. Mean \pm 1 s.e.m. values for (a) pyknotic index ((number of pyknotic nuclei plus atretic bodies/number of euchromatic granulosa cell nuclei) $\times 100)$ and $(b)$ area associated with each granulosa cell nucleus (internuclear space, a representation of cell size plus intercellular space) in cultured ovine follicles. The follicles, 2-6 mm diam., were exposed to Colcemid for $6 \mathrm{~h}$ before fixation and were non-atretic $(\mathrm{O}-\mathrm{O})$ or atretic $(---\mathbf{O})$. 
had disappeared; degenerate cells were also rare at this time. Differential cell counts made on the theca interna of follicles that had been cultured for 3 or 4 days showed that the proportion of well differentiated cells rich in tubular ER increased from $29 \%$ on Day 3, a figure similar to that found in atretic follicles in vivo (O'Shea et al., 1978a), to 43\% on Day 4; in one follicle cultured for 4 days this figure reached $56 \%$. Such cells were frequently connected by gap junctions. Another clear difference in the theca of cultured atretic follicles, as compared with non-cultured ones, was the greater number of cells with long profiles of rough ER, often arranged in parallel stacks with flattened cisternae; after 3-4 days in culture approximately $25 \%$ of thecal cells possessed this type of rough ER. Few of these cells were typically fibroblastic in appearance but they were associated with very large amounts of collagen. In atretic follicles in vivo only $5-10 \%$ of thecal cells had elongated profiles of rough ER; the amount of collagen present was much less than in vitro. It should be stressed, however, that as in the granulosa, there was interfollicular variability in the theca of the cultured follicles.

The antral cavity of atretic follicles often contained small groups or nests of exfoliated granulosa cells that were capable of dividing in culture. The follicular fluid which had a flocculent appearance in histological sections of non-atretic follicles, was often coagulated in atretic follicles that had been cultured for $72 \mathrm{~h}$ or longer and strands of fibrous material could be seen in it. This was positively identified as being fibrin and has previously been demonstrated in atretic follicles in vivo (see Hay et al., 1976: Fig. 19).

\section{Cell dynamics}

Changes in mitotic activity, pyknotic index and cell size in the granulosa layer of non-atretic and atretic follicles during the first $72 \mathrm{~h}$ in culture are shown in Text-figs 2 and 3.

Mitotic activity. In large and small non-atretic follicles, the mitotic activity was high during the first $24 \mathrm{~h}$ in culture but fell significantly between 24 and $36 \mathrm{~h}(P<0.001)$. Thereafter activity remained low in the large follicles (Text-fig. 2a) but rose in small follicles between 36 and $48 \mathrm{~h}$ $(P<0.001)$; at $72 \mathrm{~h}$, the percentage of cells in metaphase was not significantly different from that at $48 \mathrm{~h}$.

In atretic follicles, mitotic activity remained low throughout the culture period.

Pyknotic index. This was not affected by follicle size and therefore the data on the large and small follicles have been combined (Text-fig. 3a).

\section{EXPLANATION OF PLATE 1}

Fig. 1. Part of a freshly dissected $2.8 \mathrm{~mm}$ follicle in early tertiary stage of atresia. There is little differentiation visible in the theca interna. Marked degenerative changes can be seen in the granulosa layer and small atretic bodies are present along the antral border. Paraffin-wax section, stained with haematoxylin and chromotrope.

Fig. 2. Electron micrograph of part of an atretic follicle cultured for $72 \mathrm{~h}$. A greatly thickened basal lamina (BL) separates the theca interna (T) from the granulosa $(\mathrm{G})$. Collagen $(\mathrm{C})$ is present on both sides of the basal lamina and a few fibrils are present within it.

Figs 3 and 4. Paraffin-wax sections of atretic follicles cultured for $72 \mathrm{~h}$ and treated with Colcemid $\left(0.3 \mu \mathrm{g} . \mathrm{ml} \mathrm{medium}^{-1}\right)$ for $6 \mathrm{~h}$ before fixation. Stained with haematoxylin and chromotrope. Fig. 3 illustrates the most frequently seen type of regeneration of the granulosa layer. The cells have a compact arrangement and are larger than those in uncultured follicles (compare with Fig. 1). Regeneration appears to have occurred at two levels separated by a cellfree area in which small atretic bodies are trapped. Fig. 4 shows a granulosa layer consisting of an interconnecting meshwork of spindle-shaped cells. Note increased internuclear spacing (compare with Fig. 1). 


\section{PLATE 1}
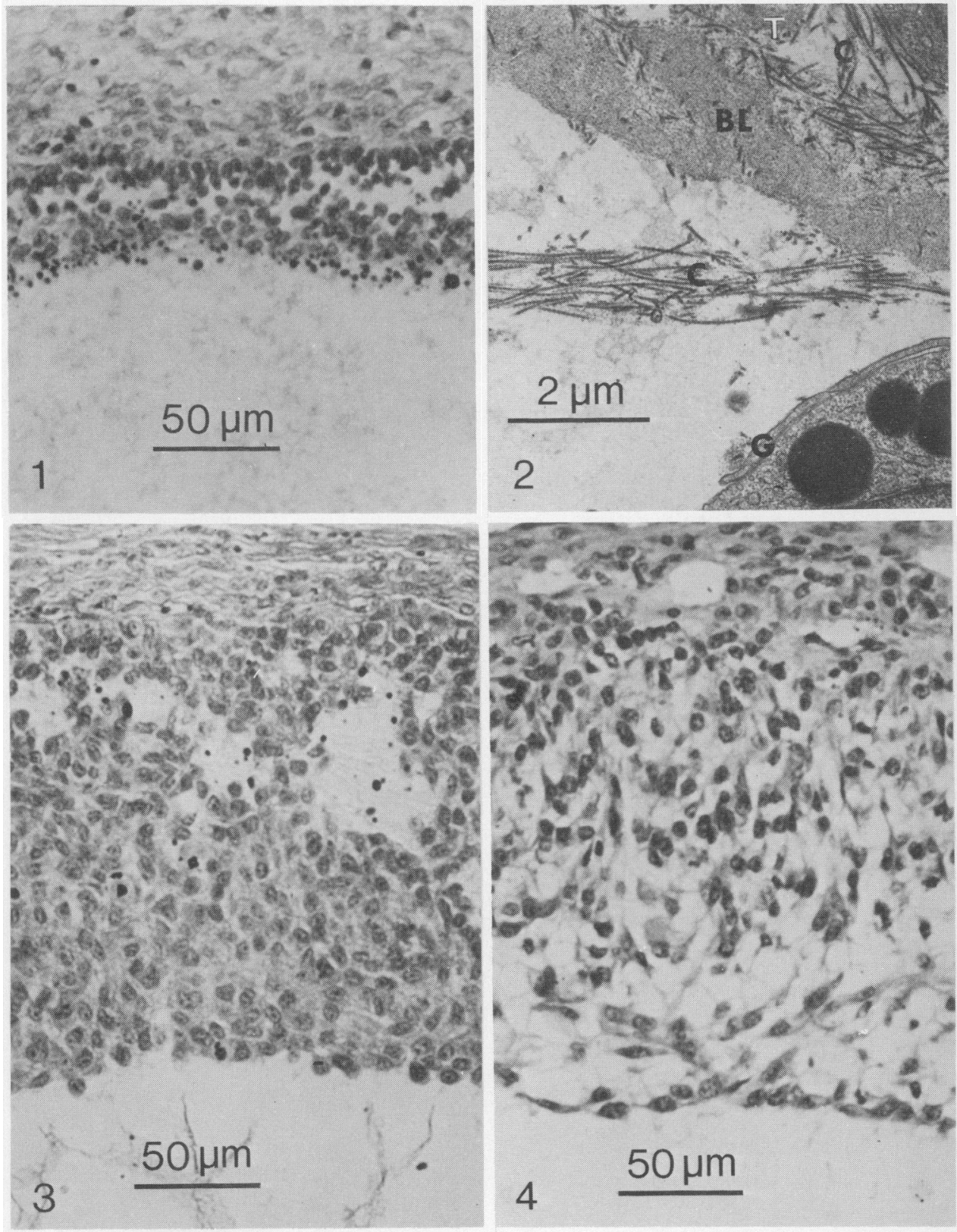

(Facing p. 200) 
In non-atretic follicles the pyknotic index in the granulosa layer remained low throughout the culture period. In atretic follicles the pyknotic index was initially high but fell precipitously during the first $36 \mathrm{~h}$ in culture to a level which was not significantly different from that in the non-atretic follicles. At $72 \mathrm{~h}$ there was a slight rise in the pyknotic index of the atretic follicles. To see whether this rise would be sustained, an additional 9 atretic follicles were cultured for $96 \mathrm{~h}$ : the index returned to a low level.

Internuclear space. This characteristic, as measured by the number of nuclei per unit area, was unaffected by follicle size. The results for the two size classes have therefore been combined (Text-fig. 3b).

In non-atretic follicles there was no change throughout the culture period. In atretic follicles, the internuclear space increased after $60 \mathrm{~h}$ in culture and this increase was sustained up to $96 \mathrm{~h}$.

\section{Steroid production}

The total amount of the three principal steroids (oestrogen + testosterone + progesterone) secreted into the culture medium by large and small, non-atretic and atretic follicles on Days 1, 3 and 5 of culture is shown in Table 1. For convenience, the sum of the values for these three major steroids is referred to in this paper as total steroid production; it is, however, known that a number of other steroids are secreted into the medium in smaller amounts (see Seamark, Moor \& McIntosh, 1974). During the first $24 \mathrm{~h}$ in culture large non-atretic follicles secreted significantly more steroid $(P<0.02)$ than large atretic ones. By Day 3 steroid output by large atretic follicles had increased almost 3-fold, and that of non-atretic follicles by approximately 2-fold, thus abolishing any differences in total steroid production between the two groups of follicles. By Day 5 steroid output by both groups had fallen, but atretic follicles were still secreting twice as much steroid as they had been on Day 1. Small non-atretic follicles also secreted more steroid than their atretic counterparts during the first $24 \mathrm{~h}$ in culture, but the difference was barely significant $(P<0.05)$. Throughout the remainder of the culture period there was little change in total steroid production by small follicles; the amount of steroid secreted by atretic follicles continued to be less, but by Day 3 the difference was no longer significant.

Table 1. Effect of follicular size and state of atresia on mean total steroid (oestradiol-17 $\beta+$ testosterone + progesterone) secreted into the culture medium

\begin{tabular}{cccccr}
\hline & \multicolumn{3}{c}{ Follicle type } \\
\cline { 2 - 3 } $\begin{array}{c}\text { Days after } \\
\text { explantation }\end{array}$ & Non-atretic & Atretic & & Non-atretic & Atretic \\
\cline { 2 - 3 } \cline { 5 - 6 } & & & & Small (2-3 mm diam.) \\
\hline 1 & $131 \pm 16$ & $79 \pm 11$ & & $126 \pm 15$ & $78 \pm 16$ \\
3 & $252 \pm 22$ & $226 \pm 23$ & & $145 \pm 16$ & $116 \pm 13$ \\
5 & $142 \pm 11$ & $155 \pm 16$ & & $114 \pm 11$ & $97 \pm 10$ \\
\hline
\end{tabular}

Values are pmol.mg follicular tissue ${ }^{-1} .24 \mathrm{~h}^{-1} \pm 1$ s.e.m., $n=20$.

The level of production of the three principal steroids is shown individually for each of the four classes of follicles in Text-fig. 4.

Large non-atretic follicles. The predominating steroid secreted (Text-fig. 4a) during the first 3 days in culture was oestrogen; the sharp rise in total steroid production on Day 3 , however, was largely due to an increase in testosterone output which accounted for $42 \%$ of the steroid secreted at that time compared with $10 \%$ on Day 1 . There was a corresponding fall in the proportion contributed by oestrogen ( $84 \%$ on Day 1 compared with $52 \%$ on Day 3 ). Progesterone secretion remained low throughout the culture period. 


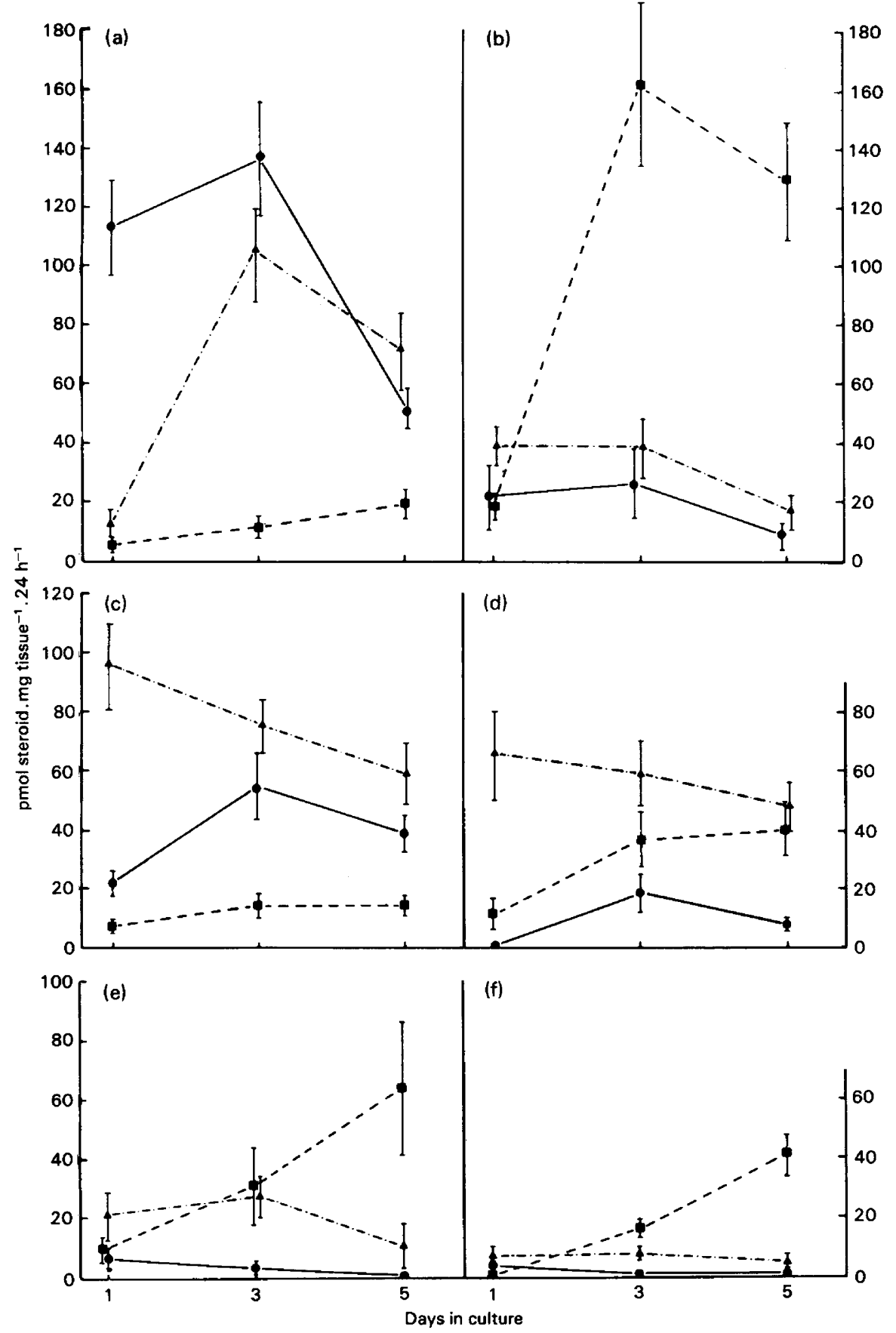

Text-fig. 4. Mean \pm 1 s.e.m. daily secretion into the culture medium of oestradiol-17 $\beta$ $(\longrightarrow)$, testosterone $(\boldsymbol{\Delta}-\cdot-\cdot-\boldsymbol{\Delta})$ and progesterone $(\boldsymbol{\square}--\mathbf{D})$ by different types of intact ovine follicles (a-d, $n=20$ ) and thecal shells (e and f, $n=15$ ). (a) Large (4-6 mm diam.) nonatretic follicles; (b) large atretic follicles; (c) small (2-3 mm diam.) non-atretic follicles; (d) small atretic follicles; (e) thecal shell of large non-atretic follicle; (f) thecal shell of large atretic follicle. 
Large atretic follicles. During the first day in culture total steroid production by these follicles (Text-fig. 4b) was only $79 \pm 11$ pmol.mg follicular tissue ${ }^{-1}$, of which $56 \pm 5 \%$ was testosterone, $26 \pm 5 \%$ progesterone and $17 \pm 6 \%$ oestrogen; by Day 3 production of progesterone alone was $161 \pm 28$ pmol and accounted for $69 \%$ of the total amount of steroid produced. Only small amounts of oestrogen were secreted.

Small non-atretic follicles. The predominating steroid produced throughout the culture period (Text-fig. 4c) was testosterone: on Day 1 it accounted for $69 \pm 6 \%$ and on Day 3 for $52 \pm 6 \%$ of the total mass of steroid secreted. Oestrogen production rose between Days 1 and 3 representing $24 \pm 6 \%$ and $39 \pm 5 \%$ of the total steroid production respectively. Only small amounts of progesterone were secreted.

Small atretic follicles. The predominating steroid during the first $24 \mathrm{~h}$ in culture (Text-fig. $4 \mathrm{~d}$ ) was again testosterone, accounting for $84 \%$ of the total steroid production. A 3 -fold increase in the amount of progesterone secreted raised the proportion of the total contributed by that steroid from $14 \pm 5 \%$ on Day 1 to $35 \pm 8 \%$ on Day 3 , with a concomitant a fall in testosterone to $51 \pm 6 \%$. The actual amounts of testosterone and also of oestrogen secreted per mg follicular tissue showed no significant change between Days 3 and 5. Oestrogen secretion was low throughout the culture period, although there was a small but significant rise on Day 3.

Thecal shells. The thecal shells of large atretic follicles were less efficient steroid producers than those of large non-atretic follicles (Text-figs $4 \mathrm{e}$ and $4 \mathrm{f}$ ). Furthermore, although the thecal shells of atretic follicles secreted some progesterone in culture, the amount was insufficient to account for that produced by intact large atretic follicles (Text-fig. 4b). In confirmation of previous studies (Moor, 1977), the thecal shell produced virtually no oestrogen. The granulosa cells of atretic follicles secreted about the same amount of progesterone as those of non-atretic follicles.

Effect of FSH on steroid production by atretic follicles. Addition of $2 \mu \mathrm{g} \mathrm{FSH} . \mathrm{ml}^{-1}$ to the culture medium did not affect the secretion of oestrogen, testosterone or progesterone by large atretic follicles (Table 2).

Table 2. Production of oestrogen, testosterone and progesterone (mean \pm s.e.m., $n=11$ ) by large atretic ovine follicles maintained in culture in the presence of $2 \mu \mathrm{g}$ FSH (NIH-S9). ml medium $^{-1}$

\begin{tabular}{ccccc}
\hline \multirow{2}{*}{$\begin{array}{c}\text { Days after } \\
\text { explantation }\end{array}$} & \multicolumn{3}{c}{ Steroid secreted into medium $\left(\mathrm{pmol} . \mathrm{mg} \mathrm{tissue}^{-1} \cdot 24 \mathrm{~h}^{-1}\right.$ ) } \\
\cline { 2 - 5 } & Total steroid & Oestrogen & Testosterone & Progesterone \\
\hline 1 & $116 \pm 13$ & $12 \pm 8$ & $89 \pm 14$ & $15 \pm 5$ \\
3 & $241 \pm 21$ & $29 \pm 10$ & $54 \pm 17$ & $158 \pm 20$ \\
5 & $167 \pm 21$ & $5 \pm 1$ & $16 \pm 5$ & $146 \pm 22$ \\
\hline
\end{tabular}

\section{Histochemical localization of $\Delta^{5}-3 \beta$-hydroxysteroid dehydrogenase activity}

After $24 \mathrm{~h}$ in culture the theca interna of non-atretic follicles showed a weak histochemical reaction for $3 \beta$-HSD which was much stronger after $48 \mathrm{~h}$. At this time there was no activity in the granulosa layer. By Day 4, enzyme activity was diminishing in the theca, but a little was present in the granulosa, particularly close to the region of the liquid-gas interface. On Day 5 the picture was substantially the same.

Atretic follicles showed almost no 3 $\beta$-HSD activity in the theca on Day 1 and considerably less than that in non-atretic follicles on Day 2. The granulosa of the atretic follicles, on the other hand, showed greater activity than that of the non-atretic ones. The granulosa of the occasional atretic follicle gave a strong positive reaction on Day 2; by Day 5 the reaction in the granulosa was consistently stronger than in non-atretic follicles cultured for the same length of time, although by no means all the regenerated granulosa cells reacted positively. 


\section{Discussion}

This study has clearly demonstrated that atresia, normally considered to be a progressive process, can be halted and to a considerable extent reversed, when atretic follicles are removed from the ovary and placed in vitro in a suitable nutrient environment. Almost complete reversal of atresia in vivo has been reported in mice treated with PMSG, although it was still possible to distinguish ultrastructurally the rescued atretic follicles from non-atretic ones (Byskov, 1978). Preliminary studies in sheep injected with PMSG led us to conclude that exogenous gonadotrophin may rescue atretic follicles in that species also (Hay \& Moor, 1978). However, more recent investigations on the size distribution of ovarian follicles and the number that were atretic at various stages after PMSG have failed to provide any direct evidence in sheep of rescue in vivo (D. G. Cran, H. M. Dott, M. F. Hay \& R. M. Moor, unpublished observations).

When atretic ovine follicles were placed in culture, morphological recovery in the theca interna approached the non-atretic condition more completely than it did in the granulosa layer. The most notable features of thecal recovery were the increase in the percentage of well differentiated cells rich in tubular ER to a value equalling that found in non-atretic follicles in vivo (O'Shea et al., 1978b) and the loss of degenerating cells and phagocytic bodies. Although regeneration of the granulosa layer was spectacular at the light microscope level, ultrastructural examination revealed that the cells failed, despite localized close apposition, to establish intercellular connections by means of gap junctions. Such junctions of the abutment and annular types are a prominent feature of the membrana granulosa in vivo in many species (see Espey \& Stutts, 1972; Merk, Albright \& Botticelli, 1973; Albertini \& Anderson, 1974; Albertini, Fawcett \& Olds, 1975; Hay \& Moor, 1975b). It is unlikely that the failure of these junctions to form in culture was due to the culture conditions per se, since individual thecal cells were connected by gap junctions. It has been suggested that oestrogen directly influences the formation of gap junctions in granulosa and other cells (Merk, Botticelli \& Albright, 1972; Azarnia \& Larsen, 1977); the absence of these junctions in the cultured atretic follicles could perhaps be attributed to lack of oestrogen. On the other hand, gap junctions appear to form readily in monolayers of granulosa cells (Lawrence, Beers \& Gilula, 1978; W. H. Fletcher, D. W. Schomberg \& J. W. Everett, personal communication) which secrete large amounts of progesterone but little or no oestrogen (Channing, 1969; Moor, 1977). Furthermore, it is possible that luteinization of granulosa cells was occurring in the atretic follicles, in which case an absence of gap junctions might be expected since they are rare in the ovine corpus luteum (D. G. Cran, M. F. Hay \& J. D. O'Shea, unpublished observations).

Progesterone secretion by the large lutein cells in sheep has been reported to involve release of granules, approximately $0.2 \mu \mathrm{m}$ diameter, which are abundant within the cells (Gemmell, Stacy \& Thorburn, 1974, 1976). If this were the sole mechanism of progesterone secretion, it would be expected that release of granules would be found in other tissue secreting high levels of progesterone. However, comparable granules were scarce in both the granulosa and theca of the cultured atretic follicles and on no occasion was any extracellular release observed.

The progressive increase in the thickness of the granulosa layer in atretic follicles (Text-fig. 1) cannot be attributed to a high level of mitotic activity as this remained consistently low throughout the first $72 \mathrm{~h}$ of culture (Text-fig. 2). The internuclear space, a measurement of cell size plus intercellular space, increased from $72 \mathrm{~h}$ onwards (Text-fig. 3b) and this could account for the greater thickness of the granulosa layer at that time but we are unable to identify the cellular events that contributed to its increased thickness during the earlier part of the culture period. Much variation in cell size occurred during that time and the ultrastructural studies have shown that there was also a scarcity of close intercellular contact. The sharp fall in pyknotic index that occurred during the first $36 \mathrm{~h}$ in culture (Text-fig. 3a) was striking. Some of the decrease in the numbers of pyknotic nuclei and atretic bodies can be accounted for by their falling to the bottom of the follicle and being excluded from the counts; phagocytosis by 
neighbouring granulosa cells also contributed to the loss. In the large non-atretic follicles the granulosa thickness was maintained throughout the culture period at a value not significantly different from that seen in uncultured follicles (shown by direct measurement and by extrapolation of the regression line back to time zero), whereas in the small non-atretic follicles the granulosa increased in thickness throughout the period at a rate not significantly different from that in small atretic follicles. The reason for the difference in behaviour of the granulosa layer between that of large and small non-atretic follicles is not known but the second burst of mitotic activity in the small follicles (Text-fig. 2 b) probably contributed towards the increased granulosa thickness apparent in them.

In this study, total steroid production has been measured in terms of oestradiol-17 $\beta$, testosterone and progesterone production. Androstenedione is another major steroid secreted in vitro by both atretic and non-atretic follicles, the testosterone: androstenedione ratio being of the order of $3: 2$ (Moor et al., 1978). Inclusion of androstenedione levels in the present study would not, however, have substantially altered the general conclusions that can be drawn from Table 1 . The essential relationship was that while total steroid output by atretic follicles in culture almost equalled that of non-atretic ones of corresponding size, the profile of steroids produced by the two types of follicles differed in a number of important ways. The most characteristic feature of steroidogenesis during early atresia was the rapid loss of aromatizing capacity and the consequent restricted synthesis of oestrogen (Moor et al., 1978); aromatizing activity was not regained during follicular regeneration despite the development of a marked capacity to synthesize $\mathrm{C}_{21}$ steroids. The irreversible loss of aromatizing activity is also readily induced in non-atretic follicles both by exposure to LH (Moor, 1974) and by the physical disruption of the association between the cells of the theca and granulosa (Moor, 1977). The apparent ability of FSH to reactivate the aromatizing enzyme system in the granulosa cells of rats (Dorrington, Moon \& Armstrong, 1975), cannot be duplicated in sheep follicles: numerous unsuccessful attempts have been made to re-establish aromatizing capacity in both atretic follicles and in nonatretic follicles treated with LH or subjected to cell separation (R. M. Moor, unpublished observations). Another characteristic of atretic follicles in vivo is their much greater capacity to synthesize androgens than can non-atretic ones of comparable size (Moor et al., 1978). However, during the regeneration of large follicles in vitro, but not of small ones, androgen secretion declined and was replaced by increased progesterone production (Text-fig. 4). Both the theca and the granulosa contributed to the marked rise in the levels of progesterone observed by Day 3 of culture.

To determine what information can be derived from our experiments about the mechanisms that cause atresia we first considered briefly some of the intraovarian and hormonal factors that have been suggested as possible inducers of atresia. Postulated intraovarian inducers include a specific atresia-promoting substance (Jones \& Krohn, 1959), reduction in blood supply leading to substrate or nutrient limitations (Greenwald, 1974; Hay et al., 1976) and the aberrant development of receptors in the theca and granulosa (Richards et al., 1978). In addition, numerous and contradictory hormonal factors have been invoked: atresia is increased by high levels of gonadotrophins (Sturgis, 1961; Harman, Louvet \& Ross, 1975), but also by their withdrawal (Keever \& Greenwald, 1967; Greenwald, 1974); oestrogen has been reported to increase atresia (Williams, 1956; Keever \& Greenwald, 1967; ter Haar, Harrison \& Peddie, 1976; Peddie, 1977) and also to have an anti-atretic effect (Ingram, 1959; Harman et al., 1975); atresia is also increased by androgens (Payne, Hellbaum \& Owens, 1956; Louvet, Harman, Shreiber \& Ross, 1975). Our experiments show that follicle regeneration occurred rapidly in vitro despite the presence of high levels of androgen, low levels of oestrogen and the virtual absence of gonadotrophins in both the follicular fluid (Moor et al., 1978) and the culture medium. Neither these findings nor the fact that androgen is the principal steroid secreted by non-atretic follicles during their growth and development lends support to the current view of a causal link between androgens and atresia. On the other hand, the concept that a reduction in 
blood supply may induce atresia is compatible with both our earlier studies on the microcirculation of atretic follicles (Hay et al., 1976; O'Shea et al., 1978a), and with the present observations that cellular -regeneration invariably occurred when atretic follicles were merely removed from the ovary and placed in a suitable nutrient environment.

The skilled technical assistance of Mr D. Green and Mrs L. Musk is gratefully acknowledged. The FSH used in this study was generously donated by the National Institute of Arthritis, Metabolism and Digestive Diseases, National Institute of Health, Bethesda, Maryland, U.S.A.

\section{References}

Albertini, D.F. \& Anderson, E. (1974) The appearance and structure of intercellular connections during the ontogeny of the rabbit ovarian follicle with particular reference to gap junctions. $J$. Cell Biol. 63, 234-250.

Albertini, D.F., Fawcett, D.W. \& Olds, P.J. (1975) Morphological variations in gap junctions of ovarian granulosa cells. Tissue \& Cell 7, 389-405.

Azarnia, R. \& Larsen, W.J. (1977) Intercellular communication and cancer. In Intercellular Communication, Chap. 6, pp. 145-172. Ed. W. C. De Mello. Plenum Press, New York.

Bjersing, L., Hay, M.F., Kann, G., Moor, R.M., Naftolin, F., Scaramuzzi, R.J., Short, R.V. \& YoungLai, E.V. (1972) Changes in gonadotrophins, ovarian steroids and follicular morphology in sheep at oestrus. $J$. Endocr. 52, 465-479.

Byskov, A.G. (1978) Atresia. In Ovarian Follicular Development and Function, (in press). Eds A. R. Midgley \& W. A. Sadler. Raven Press, New York.

Channing, C.P. (1969) The use of tissue culture of granulosa cells as a method of studying the mechanism of luteinization. In The Gonads, Chap. 9, pp. 245-275. Ed. K. W. McKerns. North-Holland Publishing Co., Amsterdam.

Dorrington, J.H., Moon, Y.S. \& Armstrong, D.T. (1975) Estradiol-17\% biosynthesis in cultured granulosa cells from hypophysectomised immature rats; stimulation by follicle-stimulating hormone. Endocrinology 97, 1328-1331.

Espey, L.L. \& Stutts, R.H. (1972) Exchange of cytoplasm between cells of the membrana granulosa in rabbit ovarian follicles. Biol. Reprod. 6, 168-175.

Gemmell, R.T., Stacy, B.D. \& Thorburn, G.D. (1974) Ultrastructural study of secretory granules in the corpus luteum of the sheep during the estrous cycle. Biol. Reprod. 11, 447-462.

Gemmell, R.T., Stacy, B.D. \& Thorburn, G.D. (1976) Morphology of the regressing corpus luteum in the ewe. Biol. Reprod. 14, 270-279.

Greenwald, G.S. (1974) Role of follicle-stimulating hormone and luteinizing hormone in follicular development and ovulation. In Handbook of Physiology, Sect. 7: Endocrinology, Vol. IV, Part 2, Chap. 33, pp. 293-323. Eds R. O. Greep \& E. B. Astwood. American Physiological Society, Washington, D.C.

Harman, S.M., Louvet, J.-P. \& Ross, G.T. (1975) Interaction of estrogen and gonadotrophins on follicular atresia. Endocrinology 96, 1145-1152.
Hay, M.F. \& Moor, R.M. (1975a) Distribution of $\Delta^{5}-3 \beta$-hydroxysteroid dehydrogenase activity in the Graafian follicle of the sheep. J. Reprod. Fert. 43, 313-322.

Hay, M.F. \& Moor, R.M. (1975b) Functional and structural relationships in the Graafian follicle population of the sheep ovary. J. Reprod. Fert. 45, 583-593.

Hay, M.F. \& Moor, R.M. (1978) Changes in the Graafian follicle population during the follicular phase of the oestrous cycle. In Control of Ovulation, Chap. 11, pp. 177-196. Eds D. B. Crighton, G. R. Foxcroft, N. B. Haynes \& G. E. Lamming. Butterworth, London.

Hay, M.F., Cran, D.G. \& Moor, R.M. (1976) Structural changes occurring during atresia in sheep ovarian follicles. Cell Tiss. Res. 169, 515-529.

Ingram, D.C. (1959) The effect of gonadotrophins and oestrogens on ovarian atresia in the immature rat. $J$. Endocr. 19, 117-122.

Jones, E.C. \& Krohn, P.L. (1959) Influence of the anterior pituitary on the ageing process in the ovary. Nature, Lond. 183, 1155-1158.

Keever, J.E. \& Greenwald, G.S. (1967) Effect of oestrogen and progesterone on pituitary gonadotrophic content of the cyclic hamster. Acta endocr., Copenh. 56, 244-254.

Lawrence, T.S., Beers, W.H. \& Gilula, N.B. (1978) Transmission of hormonal stimulation by cell-to-cell communication. Nature, Lond. 272, 501-506.

Lendrum, A.C., Fraser, D.S., Slidders, W. \& Henderson, R. (1962) Studies on the character and staining of fibrin. J. clin. Path. 15, 401-413.

Louvet, J.-P., Harman, S.M., Schreiber, J.R. \& Ross, G.T. (1975) Evidence for role of androgen in follicular maturation. Endocrinology 97, 366-372.

Merk, F.B., Botticelli, C.R. \& Albright, J.T. (1972) An intercellular response to estrogen by granulosa cells in the rat ovary; an electron microscope study. Endocrinology 90, 992-1007.

Merk, F.B., Albright, J.T. \& Botticelli, C.R. (1973) The fine structure of granulosa cell nexuses in rat ovarian follicles. Anat. Rec. 175, 107-112.

Moor, R.M. (1974) The ovarian follicle of the sheep: inhibition of oestrogen secretion by luteinizing hormone. J. Endocr. 61, 455-463.

Moor, R.M. (1977) Sites of steroid production in ovine Graafian follicles in culture. J. Endocr. 73, 143-150. 
Moor, R.M., Hay, M.F., McIntosh, J.E.A. \& Caldwell, B.V. (1973) Effect of gonadotrophins on the production of steroids by sheep ovarian follicles cultured in vitro. J. Endocr. 58, 599-611.

Moor, R.M., Hay, M.F., Dott, H.M. \& Cran, D.G. (1978) Macroscopic identification and steroidogenic function of atretic follicles in sheep. J. Endocr. 77, 309-318.

O'Shea, J.D., Hay, M.F. \& Cran, D.G. (1978a) Ultrastructural changes in the theca interna during follicular atresia in sheep. J. Reprod. Fert. 54, 183187.

O'Shea, J.D., Cran, D.G., Hay, M.F. \& Moor, R.M. (1978b) Ultrastructure of the theca interna of ovarian follicles in sheep. Cell Tiss. Res. 187, 457472.

Payne, B.W., Hellbaum, A.A. \& Owens, J.N. (1956) The effect of androgens on the ovaries and uterus of the estrogen treated hypophysectomized immature rat. Endocrinology 59, 306-316.

Peddie, M.J. (1977) Development of antral follicles and follicular atresia in guinea-pigs immunized against oestradiol-6-bovine serum albumin. J. Endocr. 75, 48-49P.

Richards, J.S., Rao, M.C. \& Ireland, J.J. (1978) Actions of pituitary gonadotrophins on the ovary. In Control of Ovulation, Chap. 12, pp. 197-216. Eds D. B. Crighton, G. R. Foxcroft, N. B. Haynes \& G. E. Lamming. Butterworth, London.

Seamark, R.F., Moor, R.M. \& McIntosh, J.E.A. (1974) Steroid hormone production by sheep ovarian follicles cultured in vitro. J. Reprod. Fert. 41, 143158.

Sturgis, S.H. (1961) Factors influencing ovulation and atresia of ovarian follicles. In Control of Ovulation, pp. 213-218. Ed. C. A. Villee. Pergamon Press, Oxford.

ter Haar, M.B., Harrison, M.A. \& Peddie, M.J. (1976) Ovarian follicular development in immature guineapigs treated with progesterone, testosterone or oestradiol from birth. J. Endocr. $68,31 P$.

Williams, P.C. (1956) The history and fate of redundant follicles. Ciba Foundation Colloquia on Ageing 2, 59-66. 